Erratum

\title{
Erratum to "Optimisation of a Generic Ionic Model of Cardiac Myocyte Electrical Activity"
}

\author{
Tianruo Guo, Amr Al Abed, Nigel H. Lovell, and Socrates Dokos \\ Graduate School of Biomedical Engineering, University of New South Wales, Sydney, NSW 2052, Australia \\ Correspondence should be addressed to Tianruo Guo; t.guo@unsw.edu.au
}

Received 27 May 2013; Accepted 28 May 2013

Copyright (C) 2013 Tianruo Guo et al. This is an open access article distributed under the Creative Commons Attribution License, which permits unrestricted use, distribution, and reproduction in any medium, provided the original work is properly cited.

A mistake occurred in (1), and it should be replaced with the following equation:

$$
\frac{d E_{m}}{d t}=-\frac{1}{C_{m}}\left(i_{\text {stim }}+i_{L}+\sum_{j=1}^{N} i_{j}\right) .
$$




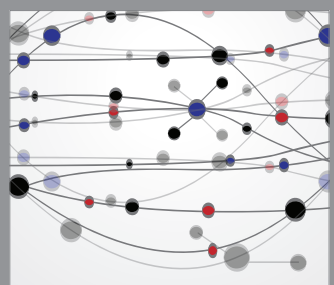

The Scientific World Journal
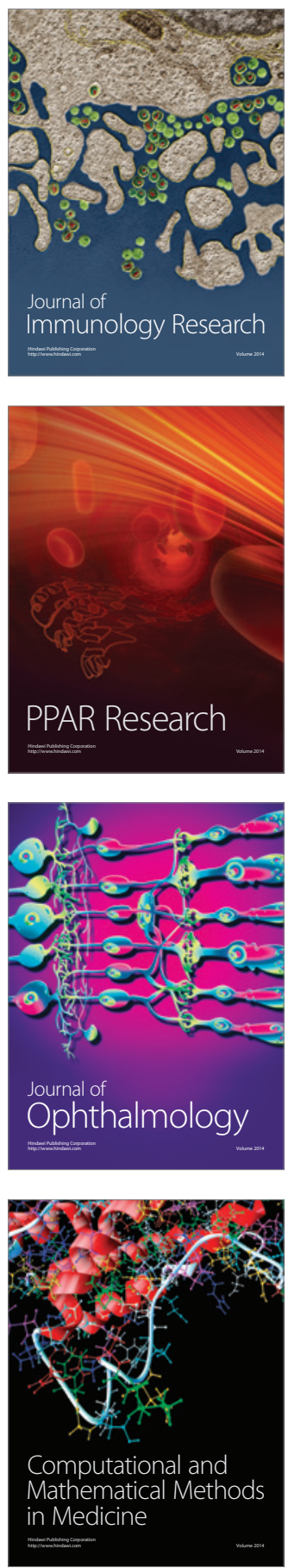

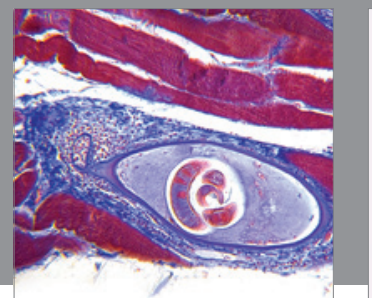

Gastroenterology

Research and Practice
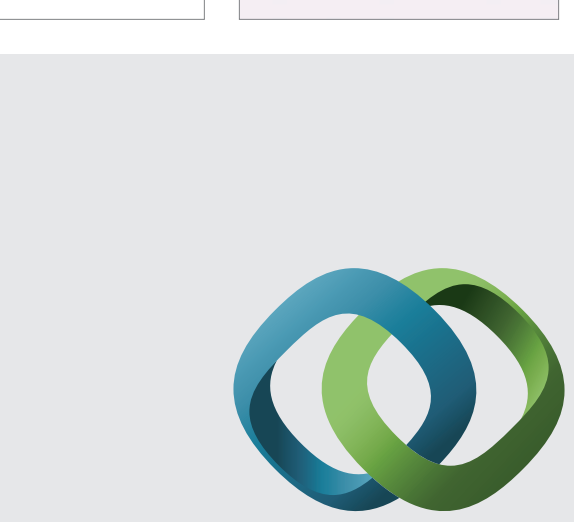

\section{Hindawi}

Submit your manuscripts at

http://www.hindawi.com
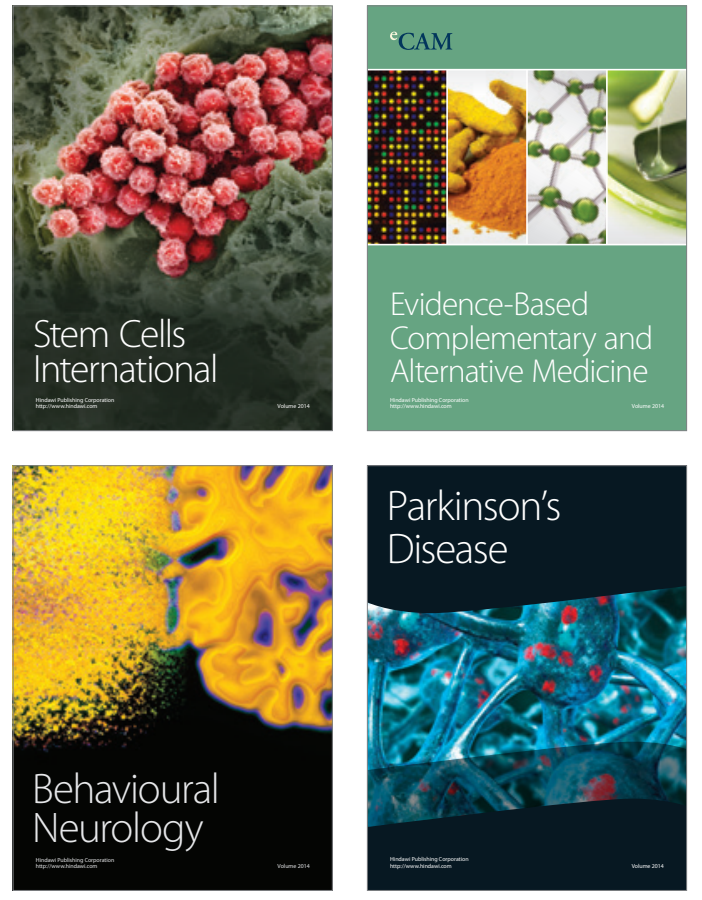
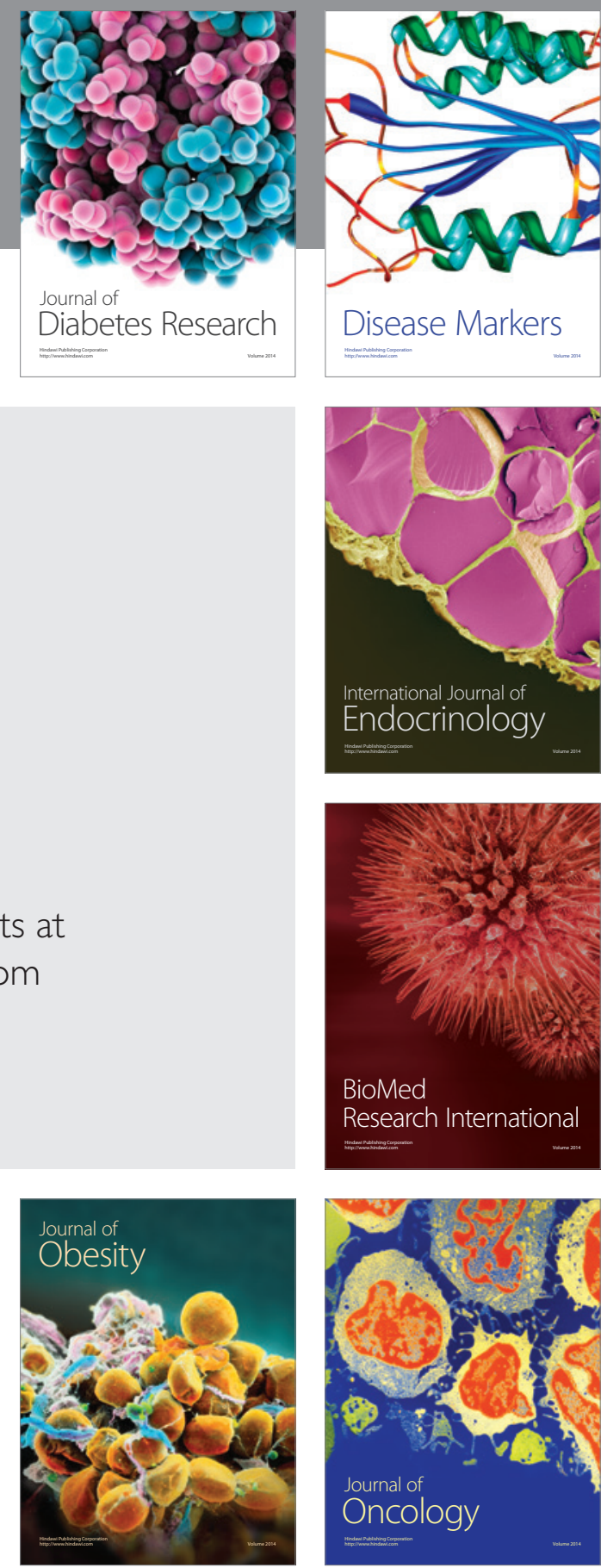

Disease Markers
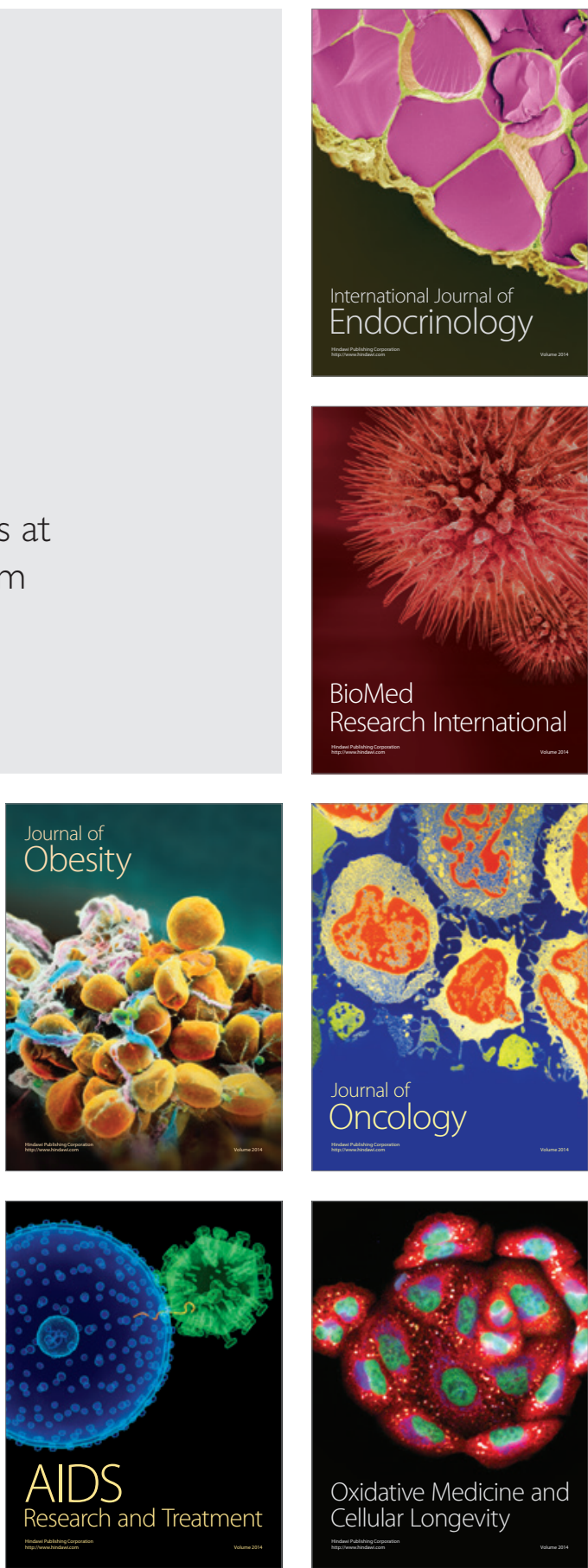